Books, videos, cd-roms, dvds and any other relevant items submitted for a review in the BDJ should be addressed to: Mike Grace, Editor, British Dental Journal, 64 Wimpole Street WIG 8YS

\section{Practical Conscious Sedation}

\author{
D. Craig, M. Skelly \\ Surrey: Quintessence, 2004 \\ price $€ 28$, pp132 \\ ISBN 185097070X
}

This is a well written, nicely illustrated practical manual on conscious sedation for dentistry. Aimed at the postgraduate dental team, it provides a comprehensive account of practical sedation techniques, as well as the fundamental underpinning principles of sedation. Easy to read with an attractive style, the book is well structured; each of the nine chapters has a clearly defined aim and outcome.

The first chapter succinctly sets the historical background to conscious sedation for dentistry and its relation to general anaesthetic practice. This is followed by chapters on relevant anatomy, physiology and pharmacology. The text on cardiorespiratory anatomy and physiology is basic but provides good revision and fulfils its title as a 'whistle-stop tour' of the topic. The pharmacology chapter contains a detailed description of the drugs available to produce conscious sedation, including those used for more advanced sedation techniques.

This is followed by a chapter giving a comprehensive outline of the proper assessment and treatment planning for sedation, which emphasises the importance of pre-sedation assessment for safe and successful treatment outcomes. The equipment, clinical techniques and complications of sedation are then detailed.

Inhalational sedation with nitrous oxide/oxygen and intravenous midazolam sedation are the mainstay of UK sedation practice and are covered well. Mention is also made of 'advanced' sedation techniques, namely benzodiazepine/opioid, intravenous propofol, oral and intranasal sedation. It is emphasised that these latter techniques should only be given by appropriately trained and experienced practitioners, but there is no mention of the necessity for anaesthetic training for those using propofol.

The final two chapters provide a useful description of the role of sedation in patients with concurrent medical problems and the contentious issue of intravenous and oral sedation in children. How to deal with failed sedation and the medico-legal implications of sedation practice and training is also covered.

At the end of each chapter there are several suggestions for further reading, although it is a shame that a more detailed list of references is not available, particularly for those who are interested in finding out more about clinical techniques and standards of sedation practice.

Overall this book is a very useful practical manual on dental sedation and should be recommended for all dental practitioners who are commencing training in sedation. It also deserves a place on the bookshelf for reference by experienced practitioners who already practise sedation.

N.M. Girdler

\section{Metal-Free Esthetic Restorations: Procera Concept}

C.E. Francischone, L.W. Vasconcelos

Surrey: Quintessence, 2003

price $€ 57, \mathrm{pp} 100$

ISBN 8587425498

This slim book of just over 100 pages is full of excellent photographs of clinical and laboratory procedures covering the Procera system. For about half the cost of a Procera crown from a laboratory the reader will discover the possibilities with this aesthetic material. Organised into two parts, Part One covers the Procera system and Part Two covers new clinical indications.

The book begins with an introduction to the Procera concept for the new user, explaining the properties and indications of this aesthetic ceramic material. The text is well presented with an easy to read style, concise and informative, with pertinent illustrations throughout. While the book covers the materials available within the Procera range, readers may seek further clarity about the different indications, for example Procera AllCeram, Procera AllTitan and Procera AllZirkon - which are all listed as the same.
Preparation design is covered and a novel method of tooth preparation where the margin is prepared first - without axial wall reduction - is illustrated. Although the photos are good quality, they portray a dentoform model. Some schematic diagrams of the ideal tooth preparations and clinical cases would be welcome. Techniques for anterior and posterior teeth are described as well as preparation guidelines for CerAdapt abutments.

The text goes on to describe an impression technique where individual acrylic copings are fabricated at chairside on each preparation. These are then used to record the impression with a polyether wash. This impression technique is not popular in the UK and readers will probably use more familiar techniques in addition to cured silicone materials. There is no mention of disinfection procedures, but the laboratory stages are covered, again with clear illustrations and minimal text based on the use of the $0.6 \mathrm{~mm}$ thick standard Procera opaque copings.

Although the first part of the book may lack the detail some may be seeking on the Procera system, it does provide a superb introduction to the use of this proven aesthetic system and would thus be wellsuited to new users. The second part of the book goes on to provide in-depth application of Procera in other situations, which will be of interest to more experienced clinicians.

Part Two describes new clinical indications such as veneers, yet the impressive case illustrated actually shows a $3 / 4$ crown preparation rather than a more conventional veneer preparation - which explains the notable outcome.

I found the section on the new translucent copings and also the use of thinner $(0.4 \mathrm{~mm})$ copings of particular interest. Another section describes the elimination of the Procera shoulder region and its replacement with shoulder ceramic to provide more cervical translucency when desired. Procera AllCeram three-unit bridges are considered with the ceramic soldering procedure illustrated in detail. A section on custom Procera abutments shows how they can be used to enhance implant retained crowns. 

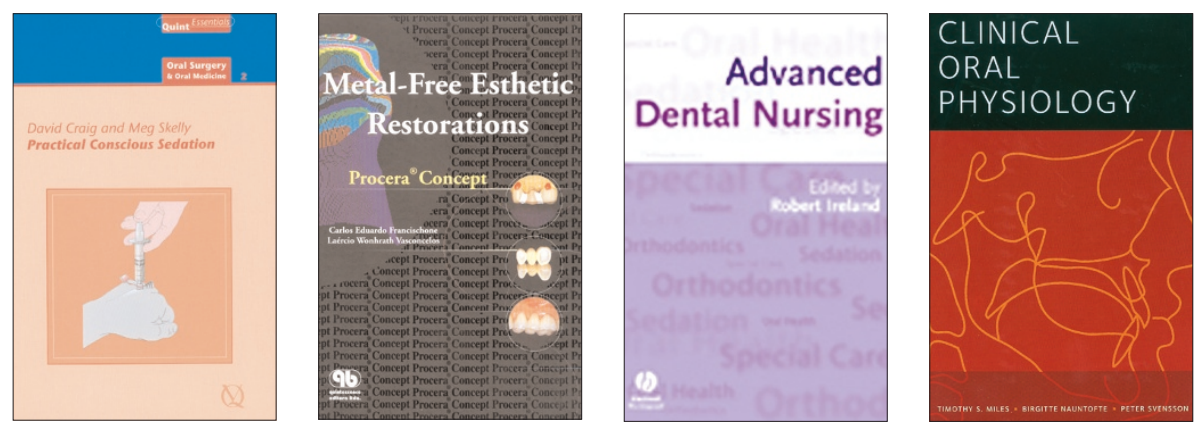

Procera AllZirkon is a new restorative option with very high fracture resistance but more opaque than the standard coping. The book finishes with a short description of the ARK project for CAD design enabling virtual surgical and prosthetic treatments based on Procera technology.

Overall, this text is of the first-rate quality we have come to expect from Quintessence. Providing reasonable depth of detail, it is easy to read and good value at $£ 57$. However, it is probably the quality and clarity of the illustrations that make this book of particular value for both new users and also those who want to go further with the Procera system.

B. Millar

\section{Advanced Dental Nursing}

R. Ireland

UK: Blackwell Munksgaard, 2004

price $\mathrm{E29.50, \text {pp326 }}$

ISBN 1405109238

With statutory registration of dental nurses

being introduced in the spring of 2005, and

the consequent introduction of CPD

requirements for re-registration, this book

is perfectly timed. Textbooks for dental nurses are a rarity, and the publication of this book provides a source for those dental nurses wishing to advance and widen their professional skills.

The book is divided into well defined clinical areas covering oral health education, special care dentistry, sedation and orthodontics. The first chapter however examines in detail the subject of career development pathways for nurses, providing much useful information, particularly on educational resources. This section is well planned and easy to read.

Under oral health education, individual areas such as care of appliances like bridges and implants, as well as dental public health, are well illustrated. However, an excellent section is on the communication of information to patients. Although a knowledge of one's subject is essential, an inability to communicate this information results in a lack of any understanding. This short section on communication is set out in an uncomplicated fashion that will be of benefit not only to nurses but dentists too.

The section special care dentistry deals with the important issue of treatment of patients who are medically compromised. It deals with this area in such depth as to act as an excellent mini directory of pathology and physiology for nurses, some of whom will find this one of the most interesting and informative chapters.

The areas of sedation and orthodontics are also covered in detail, with excellent diagrams, charts and tables. Once again the importance of a full understanding of basic anatomy and physiology and its relationship to treatment is stressed.

The success of any academic book depends to a great extent on its readability, whether we learn anything from it, and whether it is written in a style that is suitable for the intended readership. Although this book does go into considerable detail in parts, it is written in a clear and concise style, making assimilation of the content easy.

It is difficult to summarise a book of this nature - with such a wide remit - in a short review. However, I can envisage nurses reading it, whether or not they had any previous inclination to expand their knowledge, thinking, "if only I had known that, I would have understood what we are trying to achieve far better'.

I would encourage all nurses to read Advanced Dental Nursing, not just those looking to further their careers, and would also encourage any dentist who cares about the quality and training of their nurses, to purchase this excellent textbook.

M.F. Ashley

\section{Clinical Oral Physiology}

T. Miles, B. Nauntofte, P. Svensson

Surry: Quintessence, 2004

price $€ 50$, pp298

ISBN 1850970912

In Clinical Oral Physiology the editors, together with nine other authors, have assembled a novel selection of the aspects of basic science specific to dental practice and oral medicine. The intended audience is the practitioner keen to keep up with developments in the physiological and pathophysiological background to clinical problems s/he encounters. It should also be of value for undergraduate dental students, especially those following problem-based curricula, and for postgraduates in higher clinical training.

The 12 chapters cover saliva: its formation, properties and functions; taste and smell; thermosensation; orofacial pain; the tooth pulp including dentinal and pulpal pain mechanisms; mechanosensation including periodontal mechanoreceptors; masticatory muscles including the dynamics of chewing; mastication and its disorders; swallowing; speech and the effect of dental and oral disorders; oral mechanisms protective of the airways; and bone and calcium metabolism. The chapters are, reasonably, of unequal length with orofacial pain occupying 46 pages and swallowing only nine. Interestingly, the chapter on taste and smell includes a discussion of oral malodour, and that on swallowing also addresses vomiting. The text is not encumbered with references, but a selection of further reading is provided at the end of each chapter - mainly of good review articles.

There is evidence of international authorship, but the text is clear. The level of detail is well-judged: enough to inform, but not too much jargon to confuse the nonspecialist. One is always happy to discover unexpected new facts, and several of these were found, including the existence of pressure receptors in connection with implants! Inevitably the odd quibble comes to mind: some errors of proofreading, and a tendency for figures not to be on the same page as the relevant text.

How does it compare with other texts? The clinical relevance is mostly well highlighted, giving the book an advantage. On the other hand, some quite key aspects of oral biosciences are hardly covered - eg plaque, enamel, hydroxyapatite, caries, periodontal destruction, osteogenesis, and orthodontic tooth movement. The book should be assessed on its own terms - not a compendium of basic dental science, but a targeted text for a particular readership.

M.Edgar 